\title{
An IGRT margin concept for pelvic lymph nodes in high-risk prostate cancer
}

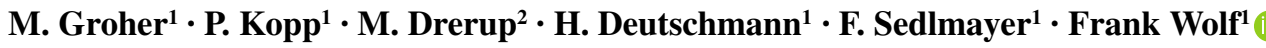

Received: 22 March 2017 / Accepted: 29 June 2017 / Published online: 19 July 2017

(c) The Author(s) 2017. This article is an open access publication.

\begin{abstract}
Purpose Gold-marker-based image-guided radiation therapy (IGRT) of the prostate allows to correct for inter- and intrafraction motion and therefore to safely reduce margins for the prostate planning target volume (PTV). However, pelvic PTVs, when coadministered in a single plan (registered to gold markers [GM]), require reassessment of the margin concept since prostate movement is independent from the pelvic bony anatomy to which the lymphatics are usually referenced to.

Methods We have therefore revisited prostate translational movement relative to the bony anatomy to obtain adequate margins for the pelvic PTVs compensating mismatch resulting from referencing pelvic target volumes to GMs in the prostate. Prostate movement was analyzed in a set of $28 \mathrm{pa}-$ tients ( 25 fractions each, totaling in 684 fractions) and the required margins calculated for the pelvic PTVs according to Van Herk's margin formula $M=2.5 \Sigma+1.64\left(\sigma^{\prime}-\sigma_{p}\right)$. Results The overall mean prostate movement relative to bony anatomy was $0.9 \pm 3.1,0.6 \pm 3.4$, and $0.0 \pm 0.7 \mathrm{~mm}$ in anterior/posterior (A/P), inferior/superior (I/S) and left/right (L/R) direction, respectively. Calculated margins to compensate for the resulting mismatch to bony anatomy were $9 / 9 / 2 \mathrm{~mm}$ in $\mathrm{A} / \mathrm{P}, \mathrm{I} / \mathrm{S}$, and $\mathrm{L} / \mathrm{R}$ direction and $10 / 11 / 6 \mathrm{~mm}$ if an additional residual error of $2 \mathrm{~mm}$ was assumed.
\end{abstract}

Dr. Frank Wolf, MD-PhD

f.wolf@salk.at

1 Department of Radiation Oncology, St. Johanns-Spital, Paracelsus Medical University of Salzburg, Müllner Hauptstraße 48, 5020 Salzburg, Austria

2 Department of Urology, St. Johanns-Spital, Paracelsus Medical University of Salzburg, Müllner Hauptstraße 48, 5020 Salzburg, Austria
Conclusion GM-based IGRT for pelvic PTVs is feasible if margins are adapted accordingly. Margins could be reduced further if systematic errors which are introduced during the planning CT were eliminated.

Keywords Prostate - IGRT - Margins · Lymph node irradiation · Gold-marker

\section{Ein IGRT-Sicherheitsrand-Konzept für den pelvinen Lymphabfluss bei Hochrisiko- Prostatakarzinom}

\section{Zusammenfassung}

Einführung Eine Goldmarker-(GM-)basierte, bildgeführte Radiotherapie der Prostata ermöglicht inter- und intrafraktionelle Bewegungen auszugleichen und somit Sicherheitsränder der Planungszielvolumina (PTV) zu minimieren. Dies gilt jedoch nicht für Zielvolumina des pelvinen Lymphabflusses, wenn diese im Rahmen eines simultan integrierten Boost-Konzepts im selben Plan verabreicht werden. Da Bewegungen der Prostata und des Lymphabflusses unabhängig voneinander sind, müssen PTV-Ränder der pelvinen Zielvolumina neu bewertet werden.

Methoden Wir haben die Relativbewegung von Prostata zur knöchernen Anatomie bestimmt, um daraus Sicherheitsränder zu generieren, die den durch Registrierung von pelvinen PTVs zu den GM resultierenden Versatz in der Prostata kompensieren. Relative Prostatabewegungen wurden bei 28 Patienten (jeweils 25 Fraktionen, 684 insgesamt) analysiert und die entsprechenden Ränder mittels der Formel nach Van Herk $M=2,5 \Sigma+1,64\left(\sigma^{\prime}-\sigma_{p}\right)$ berechnet.

Ergebnisse Die gesamte mittlere Prostatabewegung relativ zur knöchernen Anatomie betrug 0,9 $\pm 3,1,0,6 \pm 3,4$ und $0,0 \pm 0,7 \mathrm{~mm}$ in $\mathrm{A} / \mathrm{P}$ - (anterior/posterior), I/S- (inferior/ 
superior) und L/R-Richtung (links/rechts). Die berechneten Ränder der Lymphabflusszielvolumina zur Kompensation dieser Bewegungen waren 9/9/2 mm in A/P-, I/S- und L/RRichtung bzw. 10/11/6 mm unter Annahme eines zusätzlichen systematischen Fehlers von $2 \mathrm{~mm}$.

Schlussfolgerung Die GM-basierte IGRT mit Referenzierung pelviner Zielvolumina ist möglich, wenn die Sicherheitsränder entsprechend adaptiert werden, um den resultierenden Versatz zur knöchernen Struktur auszugleichen. Eine weitere Reduktion der Sicherheitsränder wäre möglich, wenn systematische Fehler, die während der Planungscomputertomographie entstehen, eliminiert werden.

Schlüsselwörter Prostata · IGRT · Sicherheitsränder · Lymphknotenbestrahlung · Goldmarker

\section{Introduction}

Elective pelvic lymph node $(\mathrm{pL})$ irradiation of high-risk prostate cancer, although discussed controversially, is common practice in many institutions and has traditionally been performed as a sequential boost regimen in normal fractionation for both prostate and $\mathrm{pL}$ planning target volumes (PTVs). Thus, the first plan including lymph node as well as prostate PTVs is typically registered to the bony anatomy whereas the following prostate boost PTV can be matched to the gold fiducials residing in the prostate.

With the advent of intensity-modulated radiotherapy (IMRT) and the recognition that prostate cancer might benefit from higher doses per fraction, simultaneous integrated boost concepts evolved and have proven feasible [1-4]. These newer concepts, however, require all PTVs to be administered within a single plan, implying that registration of prostate and pelvic PTVs can no longer be carried out separately. Therefore, PTV margins of pelvic PTVs need to be reassessed in order to compensate for mismatch resulting from relative movement of the prostate.

The prostate has been shown to move substantially within the pelvis due to differences in bladder and rectum filling [5, 6] and therefore moves independently from the pelvic bony anatomy to which the lymphatics are attached to $[7,8]$.

While the extent of intra- and interfractional prostate movement has been studied extensively [6, 9-11], data on relative movement to the bony anatomy rather than to skin markers are scarce, and margin recommendations for pelvic target volumes vary heavily [12-14].

We have therefore reassessed prostate movement relative to bony structures in a set of 28 consecutive high-risk prostate cancer patients and established margins for $\mathrm{pL}$ target volumes using Van Herk's margin formula $[15,16]$.

\section{Materials and methods}

\section{Patient preparation, contouring, and IMRT planning}

Gold marker (GM) implantation, planning CT (3 mm slice thickness), and planning MRI were performed as previously described [17]. Prior to imaging, patients were instructed to have a full bladder and to empty their bowels using mild laxatives. If bladder filling was not sufficient, the CT scan was repeated after patients were given $500 \mathrm{ml}$ to drink over a time period of $30 \mathrm{~min}$. In addition, bladder volume was assessed using an ultrasound device (Bladderscan BVI 9400, Verathon, Inc.), and a minimum bladder volume for treatment specified by the treating physician (usually between 150 and $350 \mathrm{ml}$ ). Prior to each treatment fraction, bladder volume was assessed by the radiation therapists using Bladderscan ${ }^{\mathrm{TM}}$ and checked for meeting the specifications. During the whole treatment period, patients were prescribed medication to reduce excess gas in the bowels (Antiflat, G.L. Pharma GmbH, Lannach). Contouring was performed using our in-house developed treatment and planning software Open RadART. Contouring of the prostate and seminal vesicles (sv) was performed on MRI images in transversal, sagittal, and coronal views. The final clinical target volumes (CTVs) were then contoured on the planning CT based on the superimposed MRI contours. pL CTVs were contoured on the planning CT according to RTOG contouring guidelines [18]. The upper border was the distal common iliac artery, approximately at the L5/S1 interspace. The lower border was the top of the symphysis pubis.

Inverse IMRT planning was performed using Raystation software v.4.7.2.5 (Raysearch Laboratories, Sweden). Treatment plans have been generated using either VMAT dual arc (91 segments each) or 13-field step and shoot delivering $67.5 \mathrm{~Gy}, 60 \mathrm{~Gy}$, and $50 \mathrm{~Gy}$ in 25 fractions to the prostate, sv, and $\mathrm{pL}$, respectively.

\section{Relative movement prostate-bony anatomy}

IGRT was routinely carried out using two orthogonal kilovolt images, typically at 0 and $90^{\circ}$. The X-ray images were acquired using Elekta XVI, v. 4.2 .1 at $120 \mathrm{kV}$ and $40 \mathrm{mAs}$. Contoured structures corresponding to the planning CT (such as GMs, organs at risk [OARs], and the bony anatomy) were then projected onto these planes. GM registration was performed automatically using an in-house developed algorithm [19]. Relative offsets of the actual GM positions and the planning situation were automatically transformed into executed couch translations. For our study, consecutive matching to the bony anatomy (symphysis, sacrum) was performed manually by our radiation therapists. The relative offsets of these two registrations were recorded in the anterior/posterior $(\mathrm{A} / \mathrm{P})$, infe- 
Table 1 Systematic $\left(\sum\right)$ and random $(\sigma)$ errors for each direction

\begin{tabular}{llll}
\hline & $\mathrm{A} / \mathrm{P}(\mathrm{mm})$ & $\mathrm{I} / \mathrm{S}(\mathrm{mm})$ & $\mathrm{L} / \mathrm{R}(\mathrm{mm})$ \\
\hline$\Sigma$ & 3.1 & 3.4 & 0.7 \\
$\sigma$ & 2.0 & 1.8 & 0.6 \\
$M$ & 8.5 & 9.0 & 1.9 \\
$M^{\prime}$ & 10.0 & 10.4 & 5.4 \\
\hline
\end{tabular}

$M$ is the corresponding margin using Van Herk's formula, whereas $M$, accounts for an additional systematic error $\Sigma_{S}=2 \mathrm{~mm}, A / P$ anterior/ posterior, $I / S$ inferior/superior, $L / R$ left/right

rior/superior (I/S), and left/right (L/R) directions for each fraction of each patient individually.

\section{Margin calculation}

Margin calculation based on variations in prostate position was carried out using Van Herk's margin formula $[15,16]$ : $M=2.5 \Sigma+1.64\left(\sigma^{\prime}-\sigma_{p}\right)$ where $\Sigma$ is derived by calculating the standard deviation (SD) of the mean of the daily shifts of each patient, while $\sigma^{\prime}=\sqrt{\sigma^{2}+\sigma_{p}^{2}}$ with $\sigma$ being the root mean square of the SD of the daily measurements of each patient (Table 1). $\sigma_{p}$ which correlates with the penumbra width, was set to $5 \mathrm{~mm}^{1}$. This formula ensures a minimum dose to the pL CTVs of $95 \%$ for $90 \%$ of the patient population.

\section{Results}

\section{Relative prostate movement}

In all, 28 consecutive high-risk patients who had been irradiated from July 2015 to November 2016 at University Hospital of Salzburg were analyzed in terms of relative movement of the prostate in relation to the bony anatomy of the pelvis.

In the 28 patients, a total of 684 fractions were analyzed. The overall mean prostate movement relative to bony anatomy was $0.9 \pm 3.1,0.6 \pm 3.4$, and $0.0 \pm 0.7 \mathrm{~mm}$ in the $\mathrm{A} / \mathrm{P}, \mathrm{I} / \mathrm{S}$, and $\mathrm{L} / \mathrm{R}$ directions, respectively. The distribution of prostate offsets can be seen in Fig. 1.

Interestingly, when mean prostate offset values were calculated on a patient per patient basis (Fig. 2), it became apparent that some patients exhibited larger offsets in either the $\mathrm{I} / \mathrm{S}$ or $\mathrm{A} / \mathrm{P}$ direction, whereas the standard deviation of offset values in patients remained low indicating little variability. The presence of large offset values (i.e., low precision) and low SD (i. e., high accuracy) indicates a sys-

\footnotetext{
${ }^{1}$ For average static field sizes in water a lower limit for $\sigma_{p}$ of about $3.2 \mathrm{~mm}$ is used [16]. However, for larger fields and dynamic segments as used in our study we have derived a higher value of $5 \mathrm{~mm}$.
}

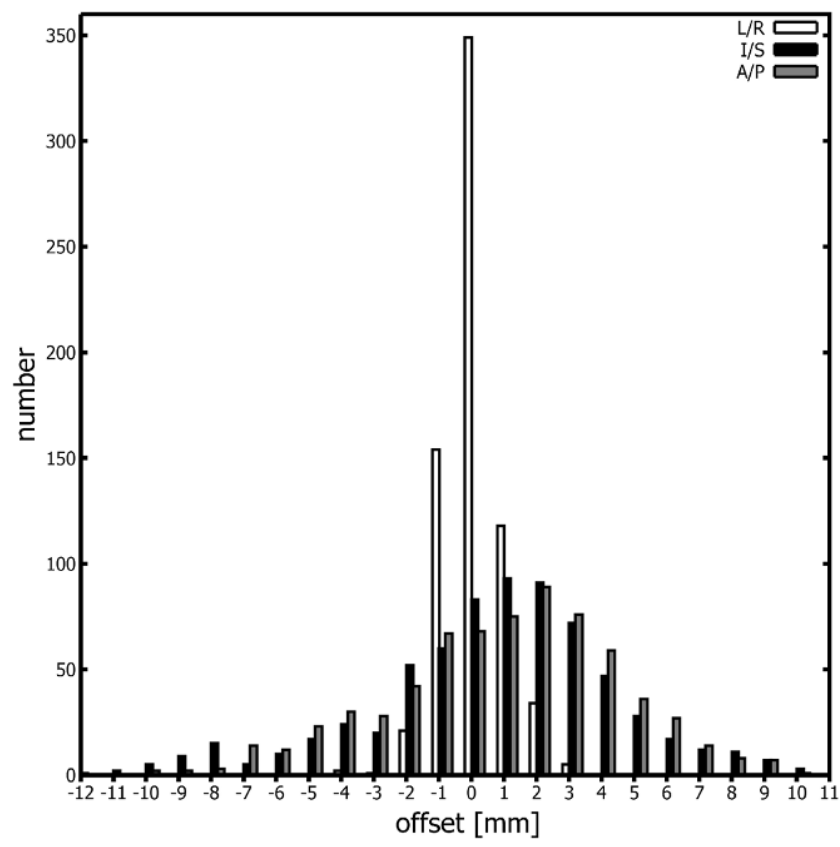

Fig. 1 Distribution of prostate offset relative to bony anatomy for 28 patients (25 fractions each). $A / P$ anterior/posterior, $I / S$ inferior/ superior, $L / R$ left/right

tematic component of the overall error, which might have been introduced in the planning CT.

\section{Margins}

In order to obtain a PTV expansion margin for a given $\mathrm{CTV}$, a number of factors need to be determined such as delineation errors, setup errors, and organ motion. With exception of the latter, these errors need to be determined by each department individually since they are dependent on machine accuracy, contouring accuracy, and treatment time. We have therefore set those errors to zero in order to obtain a margin which exclusively compensates for errors introduced as a result from mismatch of GMs to the bony anatomy due to relative prostate motion. These minimum margins for the pL PTVs read 8.5/9.0/1.9 $\mathrm{mm}$ in the A/P, $\mathrm{I} / \mathrm{S}$, and $\mathrm{L} / \mathrm{R}$ directions, respectively. Assuming an additional combined setup and delineation error of $\Sigma_{S}=2 \mathrm{~mm}$, the resulting margins would be $10.0 / 10.4 / 5.4 \mathrm{~mm}$ in the A/P, $\mathrm{I} / \mathrm{S}$, and L/R directions, respectively. We would consider these margins sufficient in the majority of modern radiation therapy units, but encourage determining the residual errors individually.

In addition, in order to quantify the influence of large systematic errors on our margins, we have identified the three patients (equivalent to about $10 \%$ of our patient population) with the largest mean displacement vector, and recalculated margins excluding them in the analysis. Resulting margins shrunk by about $1 \mathrm{~mm}$ in the $\mathrm{A} / \mathrm{P}$ and $2 \mathrm{~mm}$ 


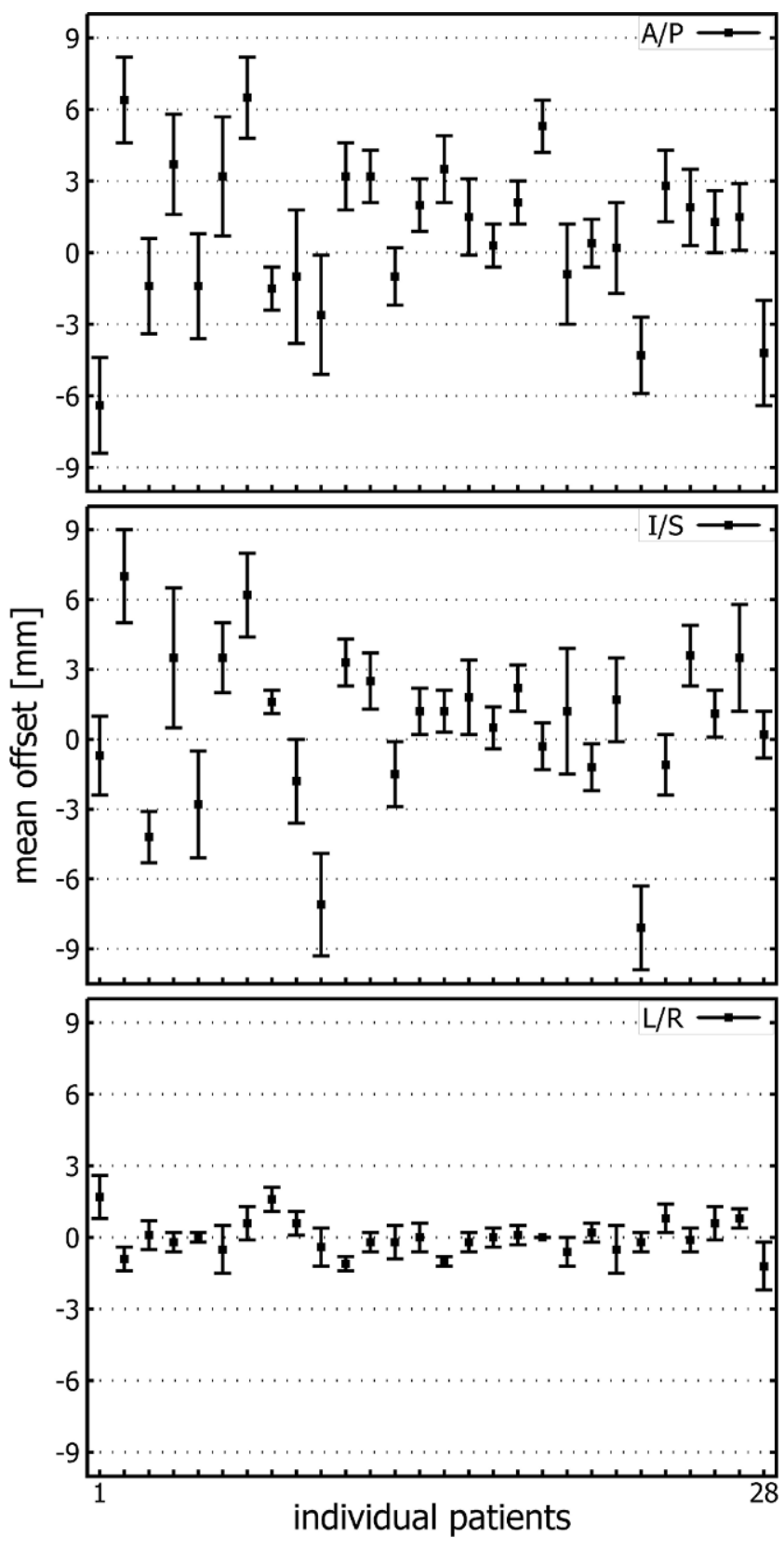

Fig. 2 Mean offset of individual patients (1-28) in the anterior/ posterior $(A / P)$, inferior/superior $(I / S)$ and left/right $(L / R)$ directions (the error bars indicate one SD)

$\mathrm{I} / \mathrm{S}$ directions and remained the same in the $\mathrm{L} / \mathrm{R}$ direction (see discussion for implications of that finding).

\section{Discussion}

In the primary external beam radiotherapy (EBRT) treatment of high-risk prostate cancer, the combination of hypofractionation to the prostate and normal fractionation to the $\mathrm{pL}$ is an attractive concept. GM-based IGRT and IMRT is recommended to minimize collateral damage to the rectum and bladder, but at the same time mandates to adjust PTV margins of pelvic PTVs to compensate for mismatch caused by the shift of prostate movement.

Rosewall et al. [20] have used a different approach to deal with that problem and have suggested to alternate image registration to GM and bony anatomy. However, since the prostate PTV receives a higher dose than the lymphatic PTVs, and because critical OARs such as the rectum and bladder are in close vicinity to the prostate, it makes sense to optimize PTV margins for the prostate rather than for (mostly elective) pelvic PTVs. Thus, we believe it is prudent to carry out IGRT registration of a plan that contains both prostate and lymph node PTVs, based on GMs rather than to the bony anatomy of the pelvis.

Others $[12,21,22]$ have analyzed dose coverage of lymph node PTVs when image registration is performed by matching to the prostate using GM- or cone beam CTbased IGRT. However, arbitrary margins of 5-10 mm were used, and dose coverage of lymph node target volumes reported by simulating prostate offset value shifts in a small number of patients. Eminowicz et al. [22] concluded that coverage is sufficient $(<0.25 \%$ coverage failure) and note in their discussion that "in an ideal setting, population based data should be used to calculate accurate CTV to PTV margins for the lymph nodes target volumes" which is exactly what we did in the present study.

We have revisited prostate movement relative to bony anatomy in a large number of 684 fractions in order to establish margins for pelvic PTV expansion which compensate for the resulting mismatch to bony anatomy when image registration is performed based on GMs in the prostate.

Our results are in good concordance with published data showing that prostate variability is very small in $\mathrm{L} / \mathrm{R}$ direction and is about the same dimension in $\mathrm{I} / \mathrm{S}$ and $\mathrm{A} / \mathrm{P}$ direction $[5,8,23]$. This is a somewhat fortunate constellation since mediolateral PTV expansion, which contributes the most to small bowel dose, can be kept small.

It has to be noted, however, that in our margin calculation contouring errors and geometrical setup errors (such as flexmap correction inaccuracies, couch translation inaccuracies, and leaf position inaccuracies) were set to zero and need to be considered before adopting the here presented margins. For demonstration purposes, we have additionally provided margins under the assumption of a $2 \mathrm{~mm}$ residual error which should be adequate in most modern radiation units. However, we strongly advise to determine these errors individually in each department.

As we have shown, systematic errors, as indicated by large offsets and small SD, are introduced during the planning CT. Such systematic errors may arise through different bladder or rectum filling/distension during planning $\mathrm{CT}$ and treatment. In this context, routine use of laxatives prior to 
the planning CT but not during treatment, might be counterproductive. In addition, systematic errors could be dealt with by documenting offset values during the first three fractions and initiating replanning when a certain threshold is exceeded.

While these data demonstrate that smaller margins could be achieved if systematic errors were detected and eliminated, it also becomes clear that a rather vast effort (i. e., detection, documentation, and analysis of all offset values during the first three fractions) needs to be invested for a rather marginal gain $(1 \mathrm{~mm}$ margin reduction in $\mathrm{A} / \mathrm{P}$ and $2 \mathrm{~mm}$ in $\mathrm{I} / \mathrm{S}$ direction).

\section{Conclusion}

We think that GM-based IGRT for plans that contain pelvic target volumes is feasible, but margins of lymphatic PTVs need to be adapted to compensate for mismatch resulting from relative movement of the prostate. Thus, $9 / 9 / 2 \mathrm{~mm}$ in the $\mathrm{A} / \mathrm{P}, \mathrm{I} / \mathrm{S}$, and lateral directions is what we would consider minimum margins; however, larger margins might be needed to compensate for errors such as residual setup error and delineation uncertainties and need to be determined individually in each institution.

Acknowledgements Open access funding provided by Paracelsus Medical University. We would like to thank Dipl. Ing. Ingrid Ziegler and Dr. Christoph Gaisberger for helpful discussion and advice. Also, we would like to thank our RTT staff for help and support in image registration processes.

\section{Compliance with ethical guidelines}

Conflict of interest M. Groher, P. Kopp, M. Drerup, H. Deutschmann, F. Sedlmayer and F. Wolf declare that they have no competing interests.

Ethical standards All procedures performed in studies involving human participants were in accordance with the ethical standards of the institutional and/or national research committee and with the 1964 Helsinki declaration and its later amendments or comparable ethical standards. Informed consent was obtained from all individual participants included in the study.

Open Access This article is distributed under the terms of the Creative Commons Attribution 4.0 International License (http:// creativecommons.org/licenses/by/4.0/), which permits unrestricted use, distribution, and reproduction in any medium, provided you give appropriate credit to the original author(s) and the source, provide a link to the Creative Commons license, and indicate if changes were made.

\section{References}

1. Engels B, Soete G, Tournel K, Bral S, De Coninck P, Verellen D, Storme G (2009) Helical tomotherapy with simultaneous integrated boost for high-risk and lymph node-positive prostate cancer: early report on acute and late toxicity. Technol Cancer Res Treat 8(5):353-359

2. Fonteyne V, Lumen N, Ost P, Van Praet C, Vandecasteele K, De Gersem Ir W, Villeirs G, De Neve W, Decaestecker K, De Meerleer G (2013) Hypofractionated intensity-modulated arc therapy for lymph node metastasized prostate cancer: early late toxicity and 3-year clinical outcome. Radiother Oncol 109(2):229-234. doi:10. 1016/j.radonc.2013.08.006

3. Kawamura H, Murata K, Takakusagi Y, Okonogi N, Kubo N, Mizukami T, Sato H, Adachi AN, Saitoh JI, Fukuma Y, Hatori M, Ohtake N, Sekihara T, Ando Y, Matsui H, Ito K, Suzuki K, Nakano $\mathrm{T}$ (2016) Simultaneous integrated boost intensity modulated radiation therapy for clinically node-positive prostate cancer. Int $\mathrm{J}$ Radiat Oncol Biol Phys 96(2S):E243-E244. doi:10.1016/j.ijrobp. 2016.06.1235

4. Hocht S, Aebersold DM, Albrecht C, Bohmer D, Flentje M, Ganswindt U, Holscher T, Martin T, Sedlmayer F, Wenz F, Zips D, Wiegel T (2017) Hypofractionated radiotherapy for localized prostate cancer. Strahlenther Onkol 193(1):1-12. doi:10.1007/ s00066-016-1041-5

5. Roeske JC, Forman JD, Mesina CF, He T, Pelizzari CA, Fontenla E, Vijayakumar S, Chen GT (1995) Evaluation of changes in the size and location of the prostate, seminal vesicles, bladder, and rectum during a course of external beam radiation therapy. Int J Radiat Oncol Biol Phys 33(5):1321-1329. doi:10.1016/03603016(95)00225-1

6. Schild SE, Casale HE, Bellefontaine LP (1993) Movements of the prostate due to rectal and bladder distension: implications for radiotherapy. Med Dosim 18(1):13-15

7. Schallenkamp JM, Herman MG, Kruse JJ, Pisansky TM (2005) Prostate position relative to pelvic bony anatomy based on intraprostatic gold markers and electronic portal imaging. Int J Radiat Oncol Biol Phys 63(3):800-811. doi:10.1016/j.ijrobp.2005.02.022

8. Hinton BK, Fiveash JB, Wu X, Dobelbower MC, Kim RY, Jacob R (2013) Optimal planning target volume margins for elective pelvic lymphatic radiotherapy in high-risk prostate cancer patients. ISRN Oncol 2013:941269. doi:10.1155/2013/941269

9. Polat B, Guenther I, Wilbert J, Goebel J, Sweeney RA, Flentje M, Guckenberger M (2008) Intra-fractional uncertainties in image-guided intensity-modulated radiotherapy (IMRT) of prostate cancer. Strahlenther Onkol 184(12):668-673. doi:10.1007/s00066008-1875-6

10. Graf R, Boehmer D, Nadobny J, Budach V, Wust P (2012) Appropriate patient instructions can reduce prostate motion. Radiat Oncol 7:125. doi: $10.1186 / 1748-717 X-7-125$

11. Li M, Ballhausen H, Hegemann NS, Reiner M, Tritschler S, Gratzke C, Manapov F, Corradini S, Ganswindt U, Belka C (2016) Comparison of prostate positioning guided by three-dimensional transperineal ultrasound and cone beam CT. Strahlenther Onkol. doi:10.1007/s00066-016-1084-7

12. Ferjani S, Huang G, Shang Q, Stephans KL, Zhong Y, Qi P, Tendulkar RD, Xia P (2013) Alignment focus of daily image guidance for concurrent treatment of prostate and pelvic lymph nodes. Int $\mathbf{J}$ Radiat Oncol Biol Phys 87(2):383-389. doi:10.1016/j.ijrobp.2013. 06.003

13. Katayama S, Habl G, Kessel K, Edler L, Debus J, Herfarth K, Sterzing F (2014) Helical intensity-modulated radiotherapy of the pelvic lymph nodes with integrated boost to the prostate bed - initial results of the PLATIN 3 Trial. BMC Cancer 14:20. doi:10.1186/14712407-14-20

14. McDonald AM, Baker CB, Popple RA, Shekar K, Yang ES, Jacob R, Cardan R, Kim RY, Fiveash JB (2014) Different rectal toxicity tolerance with and without simultaneous conventionally-fractionated pelvic lymph node treatment in patients receiving hypofractionated prostate radiotherapy. Radiat Oncol 9:129. doi:10.1186/ 1748-717X-9-129 
15. van Herk M (2004) Errors and margins in radiotherapy. Semin Radiat Oncol 14(1):52-64. doi:10.1053/j.semradonc.2003.10.003

16. van Herk M, Remeijer P, Rasch C, Lebesque JV (2000) The probability of correct target dosage: dose-population histograms for deriving treatment margins in radiotherapy. Int $\mathrm{J}$ Radiat Oncol Biol Phys 47(4):1121-1135

17. Wolf F, Gaisberger C, Ziegler I, Krenn E, Scherer P, Hruby S, Schatz T, Forstner R, Holzinger J, Vaszi A, Kametriser G, Steininger P, Deutschmann H, Sedlmayer F (2015) Comparison of two different rectal spacers in prostate cancer external beam radiotherapy in terms of rectal sparing and volume consistency. Radiother Oncol. doi:10.1016/j.radonc.2015.07.027

18. Lawton CA, Michalski J, El-Naqa I, Buyyounouski MK, Lee WR, Menard C, O’Meara E, Rosenthal SA, Ritter M, Seider M (2009) RTOG GU Radiation oncology specialists reach consensus on pelvic lymph node volumes for high-risk prostate cancer. Int $\mathrm{J}$ Radiat Oncol Biol Phys 74(2):383-387. doi:10.1016/j.ijrobp.2008. 08.002

19. Deutschmann H, Kametriser G, Steininger P, Scherer P, Scholler H, Gaisberger C, Mooslechner M, Mitterlechner B, Weichenberger H, Fastner G, Wurstbauer K, Jeschke S, Forstner R, Sedlmayer
F (2012) First clinical release of an online, adaptive, aperturebased image-guided radiotherapy strategy in intensity-modulated radiotherapy to correct for inter- and intrafractional rotations of the prostate. Int J Radiat Oncol Biol Phys 83(5):1624-1632

20. Rosewall T, Yan J, Alasti H, Cerase C, Bayley A (2016) 'Compromise position' image alignment to accommodate independent motion of multiple clinical target volumes during radiotherapy: A high risk prostate cancer example. J Med Imaging Radiat Oncol. doi:10. 1111/1754-9485.12543

21. Hsu A, Pawlicki T, Luxton G, Hara W, King CR (2007) A study of image-guided intensity-modulated radiotherapy with fiducials for localized prostate cancer including pelvic lymph nodes. Int J Radiat Oncol Biol Phys 68(3):898-902. doi:10.1016/j.ijrobp.2007.02.030

22. Eminowicz G, Dean C, Shoffren O, Macdougall N, Wells P, Muirhead R (2014) Intensity-modulated radiotherapy (IMRT) to prostate and pelvic nodes-is pelvic lymph node coverage adequate with fiducial-based image-guided radiotherapy? Br J Radiol 87(1037):20130696. doi:10.1259/bjr.20130696

23. Crook JM, Raymond Y, Salhani D, Yang H, Esche B (1995) Prostate motion during standard radiotherapy as assessed by fiducial markers. Radiother Oncol 37(1):35-42 